\title{
Effect of Anabolic Steroids on the Cardiac and Skeletal Muscles of Adult Male Rats
}

\author{
Hanan Abd-Elhakem Elgendy ${ }^{1, ~}$, Adel Abd-Elmohdy Alhawary ${ }^{1}$, Mona Abd-Elrahim El-Shahat ${ }^{1}$, \\ Afaf Taha Ali ${ }^{2}$ \\ ${ }^{1}$ Anatomy and Embryology Department, Faculty of Medicine, Mansoura University, Mansoura, Egypt \\ ${ }^{2}$ Pathology Department, Faculty of Medicine, Mansoura University, Mansoura, Egypt
}

Email address:

hananelgendy901@gmail.com (H. Abd-Elhakem E.)

${ }^{*}$ Corresponding author

\section{To cite this article:}

Hanan Abd-Elhakem Elgendy, Adel Abd-Elmohdy Alhawary, Mona Abd-Elrahim El-Shahat, Afaf Taha Ali. Effect of Anabolic Steroids on the Cardiac and Skeletal Muscles of Adult Male Rats. International Journal of Clinical and Developmental Anatomy.

Vol. 4, No. 1, 2018, pp. 1-14. doi: 10.11648/j.jicda.20180401.11

Received: November 28, 2017; Accepted: December 8, 2017; Published: February 7, 2018

\begin{abstract}
Abuse of anabolic androgenic steroids (AASs) by athletes has been increased rapidly in many countries to improve their physical fitness and appearance. The abuses of AASs have been associated with impacts on different systems of the body. The present study was conducted to evaluate the histological changes that occurred in skeletal and cardiac muscles during nandrolone (one of AASs) treatment histologically and immunohistochmically. Forty adult male albino rats were divided into four groups. Group 1; control group, group 2; was treated with nandrolone $5 \mathrm{mg} / \mathrm{kg}$ intramuscularly weekly, group 3 was treated with nandrolone $10 \mathrm{mg} / \mathrm{kg}$ intramuscularly weekly and group 4; was treated with nandrolone $20 \mathrm{mg} / \mathrm{kg}$ intramuscularly weekly. All groups were treated for 8 weeks. The specimens from the cardiac and skeletal muscles were processed for histological study using light and electron microscopes and immunohistochemical stain for detection of activated caspase-3 as an indicator for apoptotic changes. The skeletal and cardiac muscles appeared hypertrophied after nandrolone treatment. Lesions ranged from mild to severe muscular changes were also detected depending on the dose. The changes were in the form of variations of fibers size and splitting of some fibers in skeletal muscle as well as myofiber lysis, cellular infiltration, vacuolation, swelling and mitochondrial damage in both skeletal and cardiac muscles. The nuclei appeared hyperchromatic with peripherally clumped chromatin. Expression of caspase-3 was significantly increased in skeletal and cardiac tissues treated with higher doses of nandrolone. It is concluded that nandrolone injection in male albino rats induced hypertrophy and degenerative changes in the skeletal and cardiac muscles which may lead to loss of their functions.
\end{abstract}

Keywords: Nandrolone, Skeletal and Cardiac Muscles, Caspase-3, Electron Microscopy

\section{Introduction}

Anabolic steroid is a synthetic variety of the male sex hormone testosterone. The anabolic-androgenic steroid (AAS) is the expression commonly used for these compounds [1]. They are structurally and functionally similar to testosterone [2]. The androgenic effects are visible on reproductive tissues, like testes, seminal vesicle and prostate. While the anabolic effects are the nitrogen-retaining effects in muscle and bone [3]. Different mechanism of action of AAS may exist as a result of presence of variable steroid molecules with altered action on the androgen receptors.
There are various pathways of action which have been recognized. AAS is converted into dihydrotestosterone (androstanolone) by the enzyme 5-reductase. It acts on the cell nucleus of target organs, such as skin, male accessory glands and prostate [4].

The anabolic action of AAS has been seen to exert its action on protein metabolism by the induction of protein synthesis and inhibition of protein breakdown [5]. Cellular protein synthesis by androgen receptors are stimulated by anabolic steroids. They enhance growth in all tissues that have the capability to divide and grow [6]. They are frequently used clinically in many diseases such as human immunodeficiency virus-associated muscle wasting [7], 
prostate cancer, benign prostate hyperplasia, well-known androgen-dependent diseases, management of the anemia of renal insufficiency, osteoprosis, growth deficiency, in extreme debilitating disease such as ulcerative colitis, after major surgery and also in severe burns [8, 9].

Some athletes use anabolic androgenic steroids (AAS) to enhance performance regardless of the health risk they may impact in some persons [10]. Very high doses of AAS have been used by athletes to improve muscle strength and physical appearance, which is the principle to increase the performance of the athletic. A variety of AASs have been used simultaneously (so-called "stacking") and in high doses that result in 10-100-fold raises in androgen concentration [11].

Amongst the various recorded hormonal and toxic impacts of AAS, a lot of work interest has been done on the cardiovascular influences of AAS. Many negative deleterious cardiovascular outcomes, like depression of high density lipoprotein, hypertension and sudden cardiac death have been reported [12]. Other negative actions on the heart include cardiac rupture, breakdown of the functional syncytium and worsening of the cardiac function. Cell death signaling has been found along with cardiomyopathy, myocardial infarction and sudden death [13, 14].

Apoptosis induced by testosterone overdosing has been cleared [15]. Testosterone causes apoptosis in smooth muscle cells of blood vesseles using the extrinsic apoptotic pathway that involves androgen receptor activation and reactive oxygen species generated from mitochondria [16]. Apoptosis causes the loss of myocardial cells and ultimately the depression of myocardial performance. Myocardial death without coronary vessel disease or atherosclerosis has also been attributed to the activation of apoptosis by AAS [17].

Hence, the aim of this work was to study the changes that could occur in skeletal and cardiac muscles during the administration of nandrolone (one of AAS) histologically by using light and electron microscopes and immunohistochmically to detect csapase-3 immunoexpression as an indicator for apoptotic changes in skeletal and cardiac muscles.

\section{Materials and Methods}

The present study was performed on 40 adult healthy male albino rats (Sprague Dawley), weighing from 200 to $250 \mathrm{gm}$. They were kept in stainless steel mesh cages under controlled condition of temperature $\left(23^{\circ} \mathrm{C} \pm 3\right)$, and relative humidity. The animals had free approach to standard commercial diet and tap water ad libitum with a 12-h light-dark cycle throughout acclimatization and experimental periods.

\subsection{Experimental Design}

After 1 week of acclimatization, the rats were randomly divided into 4 groups:

1. Group 1 (control group) (10 rats): that subdivided into two subgroups:

Control subgroup 1A: negative control given diet and water only.

Control subgroup 1B: vehicle control group, that injected by corn oil the same volume injected in the experimental groups intramuscular in the gluteal region once weekly for 8 weeks

2. Group 2 (low dose group) (10 rats): this group was treated with nandrolone $5 \mathrm{mg} / \mathrm{kg}$ body weight intramuscularly weekly for 8 weeks.

3. Group 3 (moderate dose group) (10 rats): this group was treated with nandrolone $10 \mathrm{mg} / \mathrm{kg}$ body weight intramuscularly weekly for 8 weeks.

4. Group 4 (high dose group) (10 rats): this group is treated with nandrolone $20 \mathrm{mg} / \mathrm{kg}$ body weight intramuscularly weekly for 8 weeks.

Nadrolone decanoate was purchased from the Nile Company for pharmaceuticals (Egypt), in the form of oily solution ampoule $(25 \mathrm{mg} / \mathrm{ml})$. The ampoule was diluted in 5 $\mathrm{ml}$ of corn oil to get concentration of $5 \mathrm{mg} / \mathrm{ml}$.

During the entire experiment, the rats were periodically weighed every two weeks. After 24 hours from the end of the experiment, all rats were sacrificed under ether anesthesia. The heart specimens were taken from the anterior-lateral wall of the left ventricle near the apex [18]. Skeletal muscle specimens were taken from the shoulder girdle. The specimens from both heart and skeletal muscles were prepared for light and electron microscopic examination.

\subsection{Light Microscopic Study}

The muscle specimens were taken and immediately fixed in $10 \%$ formol saline solution for 24 hours, dehydrated and impregnated in paraffin. Sections of five micron in thickness were cut and stained with Hematoxylin and Eosin (H\&E) [19] or Caspase-3 immunohistochemistry.

In Caspase-3 immunohistochemistry; five $\mu \mathrm{m}$ sections of were deparaffinized, hydrated, treated with trypsin solution for $15 \mathrm{~min}$ at $37{ }^{\mathrm{O}} \mathrm{C}$ for antigen retrieval and then were exposed to $0.2 \%$ hydrogen peroxide in phosphate buffered saline (PBS) to block endogenous peroxidase for $30 \mathrm{~min}$. Sections were then incubated overnight at $4 \mathrm{C}^{\mathrm{o}}$ with primary rabbit anti-rat caspase-3 antibody (NewMarkers, Fremont CA, Lab Vision). The sections were then washed three times in PBS and incubated with goat anti-rabbit peroxidaseconjugated secondary antibody (Peroxidase-labelled streptavidin) for 1 hour at room temperature. After washing with PBS, sections were incubated with diaminobenzidine (DAB) chromogen to detect immunoreactivity. Counterstaining was performed by Mayer's hematoxylin. Positive reaction for caspase 3 was appeared as brown coloration of the cytoplasm. For negative control, phosphate buffer solution replaced the primary antibody, while other steps of the procedure were the same [20].

\subsection{Electron Microscopic Study}

The specimens were fixed in $1 \%$ phosphate buffered glutaraldhyde ( $\mathrm{pH}$ 7.2-7.4) and post fixed in freshly prepared $1 \%$ osmium tetroxide (osmic acid) in phosphate buffer at $4^{\circ} \mathrm{C}$ for $1-2$ hours. Ultra-thin sections were stained with $4 \%$ uranylacetate and lead citrate. The grids were examined and photographed with transmission 
electron microscope (Jeol, Japan) in the Electron Microscopy Unit, Tanta University [21].

\subsection{Quantitative Measurement and Statistical Analysis}

Optical density of caspase-3 positive immunoreaction in the cardiac and skeletal muscle cells was estimated at a magnification of $\times 400$ in ten randomly chosen nonoverlapping fields in five slides of each animal of each group. It was measured by using the color detect menu and in relation to a standard measuring frame $\left(20 \mathrm{~mm}^{2}\right.$ frame) by using image J 1.47 software (Wayne Rasband, USA) carried out in Image unit, Histology department, Faculty of Medicine, Tanta University, Egypt. The cellular labeling of activated caspase-3 subunits was visualized in the cytoplasm and/or nuclei.

All data of Optical density of caspase-3 positive immunoreactions and periodic record of body weights were presented as mean \pm SD using the statistical package for social sciences (version 11.5; SPSS Inc., Chicago, Illinois, USA) statistical analysis software. The significance of difference between groups was tested using ANOVA (one way analysis of variance) followed by post-hoc tukey for multiple comparisons. The level of significance was set at $P \leq 0.05$.

\section{Results}

\subsection{Statistical Studies}

\subsubsection{Body Weight}

The mean initial body weight of both the control and experimental animals was around 225 grams.

Group I (Control group):

Rats of control subgroup which was injected with corn oil showed no significant difference in the body weight compared to the negative control subgroup1A.

Experimental groups:

Rats of both low-dose, and moderate-dose nandrolone treated groups showed a similar growth with no difference in the body weight gain compared to the control group. In contrast, the high-dose-treated animals showed stunted growth from 2 wk of treatment on $(\mathrm{P}<0.05)$, leading to a final body weight of $82 \%$ of both other groups $(\mathrm{P}<0.05)$ (table 1$)$.

Table 1. Comparison of body weight (in grams) between control group and experimental groups measured every two weeks.

\begin{tabular}{|c|c|c|c|c|c|c|c|}
\hline Animal Weight & Control & $\begin{array}{l}\text { Group } 2 \text { (Low } \\
\text { Dose) }\end{array}$ & $\begin{array}{l}\text { "P" } \\
\text { Value }\end{array}$ & $\begin{array}{l}\text { Group } 3 \text { (Moderate } \\
\text { Dose) }\end{array}$ & $\begin{array}{l}\text { "P" } \\
\text { Value }\end{array}$ & Group 4 (High Dose) & "P" Value \\
\hline Initial weight Mean \pm S. D & $220.66 \pm 15.45$ & $222.83 \pm 18.87$ & $>0.05$ & $225.66 \pm 17.98$ & $>0.05$ & $227.41 \pm 18.56$ & 0.978 \\
\hline Week 2 Mean \pm S. D & $235.33 \pm 18.56$ & $238.58 \pm 20.45$ & $>0.05$ & $232.91 \pm 21.48$ & $>0.05$ & $229.41 \pm 21.23$ & $<0.05$ \\
\hline Week 4 Mean \pm S. D & $256.5 \pm 16.44$ & $258.12 \pm 21.65$ & $>0.05$ & $253 \pm 19.43$ & $>0.05$ & $248.75 \pm 21.19$ & $<0.05$ \\
\hline Week 6 Mean \pm S. D & $274.67 \pm 19.66$ & $271.34 \pm 22.34$ & $>0.05$ & $273.26 \pm 21.45$ & $>0.05$ & $252 \pm 14.86$ & $<0.05$ \\
\hline Week 8 Mean \pm S. D & $296.5 \pm 15.86$ & $294 \pm 23.61$ & $>0.05$ & $293.45 \pm 18.34$ & $>0.05$ & $241 \pm 19.65$ & $<0.05$ \\
\hline
\end{tabular}

Data expressed as mean \pm standard deviation, tested using ANOVA (analysis of variance) followed by post-hoc tukey. $\mathrm{P}<0.05$ is significant.

\subsubsection{Caspase-3 Immunohistochemistry}

In skeletal muscle cells, there was a significant increase $(\mathrm{P}$ $<0.05)$ in optical density of caspase-3 positive cells in nandrolone - treated animals with moderate dose (Group 3) and a highly significant increase $(\mathrm{P}<0.001)$ in nandrolone treated animals with high dose (Group 4) compared to control animals. However, there was no statistical difference between the optical density of caspase- 3 positive cells in group II and control animals (Table: 2). But, in cardiac muscle cells all experimental groups showed either significant increase $(\mathrm{P}<0.05)$ or highly significant increase $(\mathrm{P}<0.001)$ in the optical density of caspase- 3 positive cells compared to control animals (Table 3 ).

Table 2. The mean of optical density of Caspase-3 immunoreaction in skeletal muscle cells in the different studied groups.

\begin{tabular}{lll}
\hline Skeletal muscle groups & $\begin{array}{l}\text { Mean optical density of } \\
\text { caspase 3 reactions }\end{array}$ & P Value \\
\hline Group 1 (control) & $2.346 \pm 0.782$ & \\
Group 2 & $3.667 \pm 0.823$ & 0.745 \\
Group 3 & $25.876 \pm 4.67$ & 0.03 \\
Group 4 & $31.934 \pm 6.48$ & 0.001 \\
\hline
\end{tabular}

Data expressed as mean \pm standard deviation, tested using ANOVA (analysis of variance) followed by post-hoc tukey. $\mathrm{P}<0.05$ is significant. $\mathrm{P}<0.001$ is highly significant.
Table 3. The mean of optical density of Caspase-3 immunoreaction in cardiac muscle cells in the different studied groups.

\begin{tabular}{lll}
\hline Cardiac Muscle groups & $\begin{array}{l}\text { Mean optical density of } \\
\text { caspase 3 reactions }\end{array}$ & P Value \\
\hline Group 1 (control) & $7.894 \pm 1.23$ & \\
Group 2 & $29.563 \pm 2.5$ & 0.01 \\
Group 3 & $39.678 \pm 3.57$ & 0.001 \\
Group 4 & $53.786 \pm 5.78$ & 0.001 \\
\hline
\end{tabular}

Data expressed as mean \pm standard deviation, tested using ANOVA (analysis of variance) followed by post-hoc tukey. $\mathrm{P}<0.05$ is significant. $\mathrm{P}<0.001$ is highly significant.

\subsection{Microscopic Results}

\subsubsection{Light Microscopic Results of Skeletal Muscle}

Group I (Control group):

Examination of H\&E stained sections of the control subgroups revealed normal structure of skeletal muscle. It was formed of bundles of skeletal muscle fibers surrounded by normal $\mathrm{C}$. $\mathrm{T}$ partitions in transverse and longitudinal sections (Figure 1a-b.). Immunohistochemical detection of myocyte-specific caspase 3 showed no apparent difference in the myocytes reactions of control subgroups as few muscle cells with weak reaction were noticed (Figure 1c)

Experimental groups treated with nandrolone for eight weeks:

Light microscopic examination of the skeletal specimens 
of treated rats revealed progressive histological alterations in a dose dependent manner (Figures. 2-4). H\&E stained sections revealed hypertrophy of skeletal muscle fibers which were dose related and became more obvious at the high dose used. Muscle fibers showed mild focal changes at low dose which progressively increased at high dose. The muscle sections showed widening of the space in-between muscle fibers and the fibers appeared irregular in size. Splitting of muscle fibers was also observed, which appeared as a transverse invagination or complete separation of the sarcolemmal membrane. Some muscle fibers showed internalization of the nuclei. Dilation and congestion of blood capillaries with mild mononuclear cellular infiltration inbetween muscle bundles were also observed. Mild to severe degenerative changes in the form of focal lysis with disturbed transverse striations, swelling and cytoplasmic vacuolation of muscle fibers were also noticed. Examination of caspase-3 stained showed mild to marked immunostaining reaction according to the dose used (Figure 5).

\subsubsection{Light Microscopic Results of Cardiac Muscle}

Group I (Control group):

Examination of H\&E stained sections of the cardiac muscle from left ventricle of control subgroups revealed normal structure. The muscle fibers were mostly long cylindrical striated cells with one or two, large, oval centrally located nuclei. The sarcoplasm appeared eosinophilic. They appeared in cross sections as elliptical or lobulated eosinophilic structures with nearly centrally located basophilic nuclei. The myoctes were separated by a delicate layer of connective tissue with well evidenced myocardial blood capillaries (Figure 6a). Immunohistochemically, caspase-3 expression was rarely seen in the cardiac muscle cells of control subgroups (Figure 6b).

Animals treated with nandrolone for eight weeks:

H\&E stained sections revealed histological changes in a dose dependent manner (Figures. 7-9). The cardiac myocytes appeared hypertrophied at moderate and high doses and the cytoplasm of many cardiac myocytes was pale acidophilic displaying marked fibrillolysis with disturbed transverse striations and established many cytoplasmic and perinuclear vacuolation. These changes were accompanied with nuclear peripheralization and pyknosis. These changes were also associated with congestion of myocardial blood vessels, an increase in the connective tissue matrix in between the cardiac muscle fibers as well as mononuclear cellular infiltration. Caspase-3 immunostaining showed mild to marked expression in myocytes according to the used dose (Figure 10).

\subsubsection{Transmission Electron Microscopic Results of Skeletal Muscle}

Group I (Control group):

Examination of longitudinal sections of the deltoid muscle fibers of control subgroups revealed the normal electron microscopic picture of skeletal muscle fibers. The myofibrils were arranged parallel to the long axis of the myofiber and had regular alternating light (I) and dark (A) bands. Z line was seen bisecting the light band. There were paired thin mitochondria separating the myofibrils at the I-band level and few mitochondria were also observed at the subsarcolemmal area. The myocyte was limited by sarcolemma and adherent basal lamina. The sarcoplasmic vesicles were found between the myofibrils (Figure 11).

Animals treated with nandrolone for eight weeks:

The transmission electron microscopic changes observed in experimental rats showed focal damage of the skeletal muscle ranging from minimal to severe in accordance with the dose of nandrolone. The damaged cells were often present side by side with the normally appeared cells (Figures. 12-14).

The muscle sections showed focal disorganization and discontinuation of myofibrils together with focal area of discontinuation and loss of $\mathrm{Z}$ lines. Accumulations of the mitochondria in the subsarcolemmal space and in between myofibrilis were noticed. Swollen and damaged mitochondria with vacuolation of their matrix were occasionally seen according to the dose used. Dilatation of the sarcoplasmic reticulum was observed in the place of destroyed muscle fibers. The nuclei appeared in the center of some myoctes. Nuclear changes in the form of internalization of the nucleus with irregularity of its outline were observed (Figures. 13C \& 14D).

\subsubsection{Transmission Electron Microscopic Results of Cardiac Muscle}

Group I (Control group):

Examination of cardiac myocyes of control subgroups revealed the normal electron microscopic picture of cardiac muscle fibers. The cardiac myocytes were limited by sarcolemma. They were closely opposing, branching, striated and attached end to end by intercalated discs. Each cardiac myocyte contained a central oval euchromatic nucleus with a prominent nucleolus. The myofibrils were arranged in sarcomeres between Z-lines with the dark A-band in the middle and light I-band in the periphery. Between the myofibrils the sarcoplasmic reticulum and uniformly distributed mitochondria in rows were seen separating the cardiac myofibrils in association with scattered glycogen granules (Figure 15a-b).

Animals treated with nandrolone for 8 weeks:

The transmission electron microscopic changes observed in experimental rats showed focal damage of the cardiac muscle ranging from minimal to severe in accordance with the dose of nandrolone. The damaged cells were often present side by side with the normally appeared cells (Figures.16-18). The myocardium revealed focal areas of fragmentation and lysis of the myofibrils in some myocytes with disruption of myofibrils. In some cells there were loss of the uniform thickness pattern of myofibrils and some were split. The mitochondria were disorganized, pleomorphic revealing variation in their size. Some mitochondria appeared swollen, destroyed and vacuolated. In some myofibers the mitochondria were swollen and accumulated under the sarcolemma and inbetween the myofibrils. Dilated smooth 
endoplasmic reticulum was also seen in some myocytes. Nuclear changes in the form of peripherlization, irregular

outline and peripheral chromatin condensation were also observed.
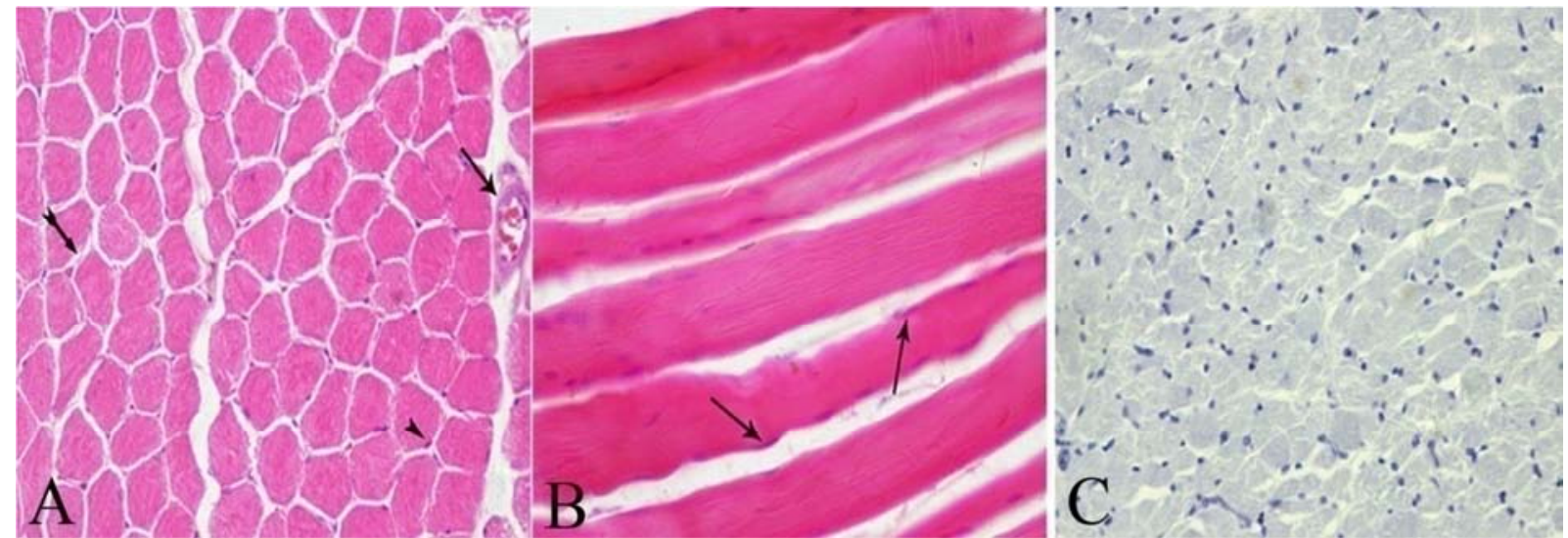

Figure 1. (A) Transverse section of a skeletal muscle of control rat showing bundles of skeletal muscle fibers. The muscle fibers are separated by CT, endomysium $(\rightarrow)$ and they appear polygonal with peripherally located nuclei (>). Blood vessel is seen between muscle bundle in perimysium $(\rightarrow)$. (B) Longitudinal section showing parallel muscle fibers with peripherally located nuclei $(\rightarrow)$. (C) Transverse section showing very weak or absence of caspase-3 positive immuno-reaction (A\&B: $H \& E ; x$ 400, C: Caspase-3 immunostaining; X 400).

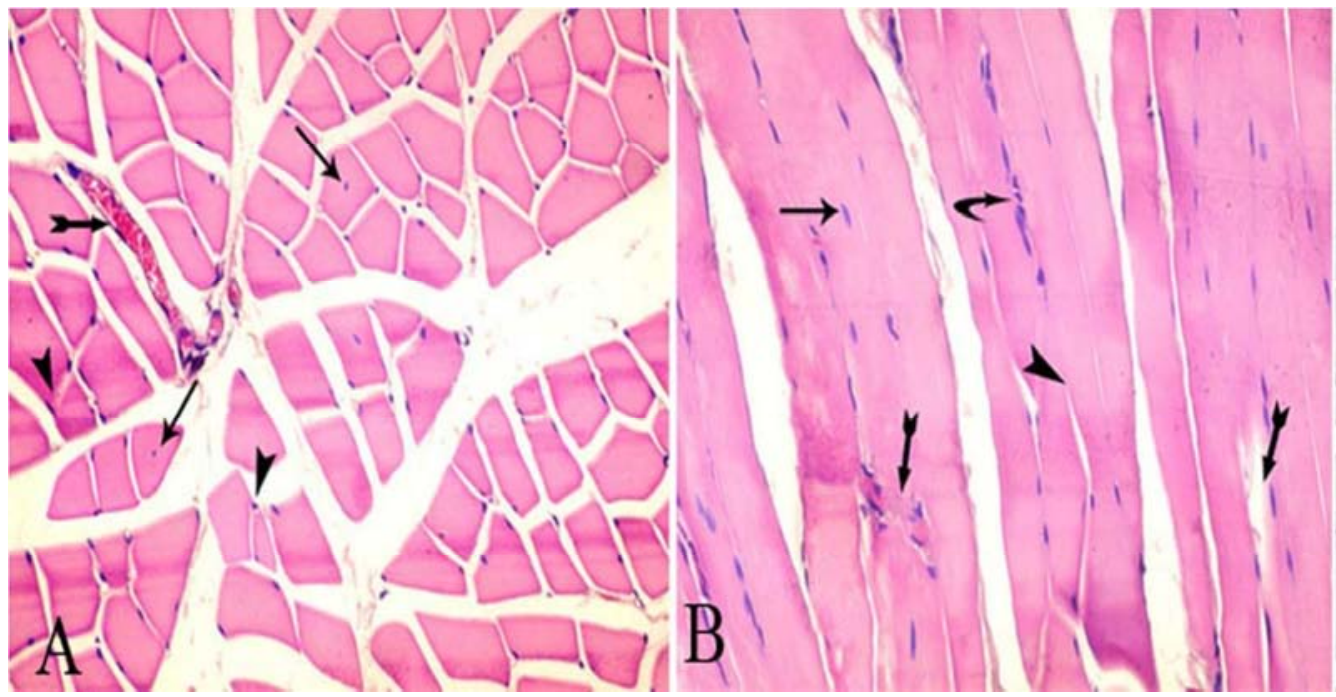

Figure 2. (A) Transverse section of a skeletal muscle of a rat in group 2 showing mild variation of fiber size \& shape, internalization of some myonuclei $(\rightarrow)$ and muscle fiber splitting ( $($ ). Notice the dilatation and congestion of blood capillaries $(\rightarrow)$. (B) Longitudinal section showing focal lysis and vacuolation in some muscle fibers $(\rightarrow)$, internal myonuclei $(\rightarrow)$, and mononuclear cellular infiltration (curved arrow) $(H \& E ; x 400)$.
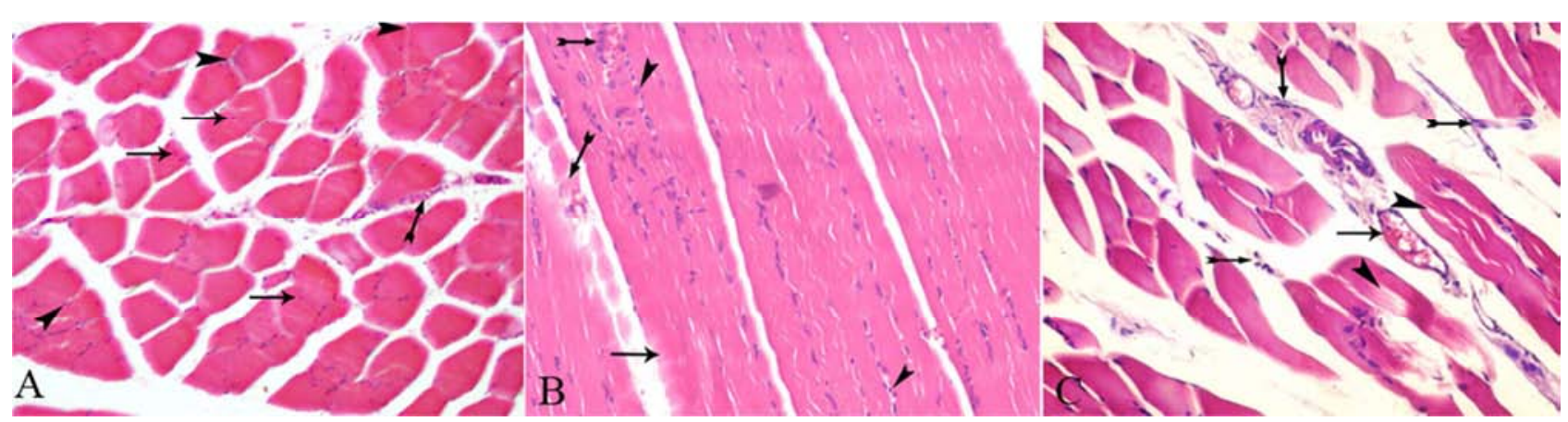

Figure 3. (A) Transverse section of a skeletal muscle of a rat in group 3 showing hypertrophy of many fibers, internal myonuclei $(\rightarrow)$, mononuclear cellular infilitrations in between muscle fibers ( $\rightarrow$ ) and splitting of muscle fiber (•). (B) Longitudinal section showing focal lysis ( $\rightarrow$ ) with mononuclear cellular infiltration inbetween muscle fibers (>) and disturbed transverse striations $(\rightarrow)$. (C) Transverse section showing swollen muscle fibers with clear separation between myofibrils (>), dilated blood capillaries $(\rightarrow)$ and mononuclear cellular infiltration $(\rightarrow)$ in-between muscle fibers $(H \& E ; A \times 200, B \& C \times 400)$. 

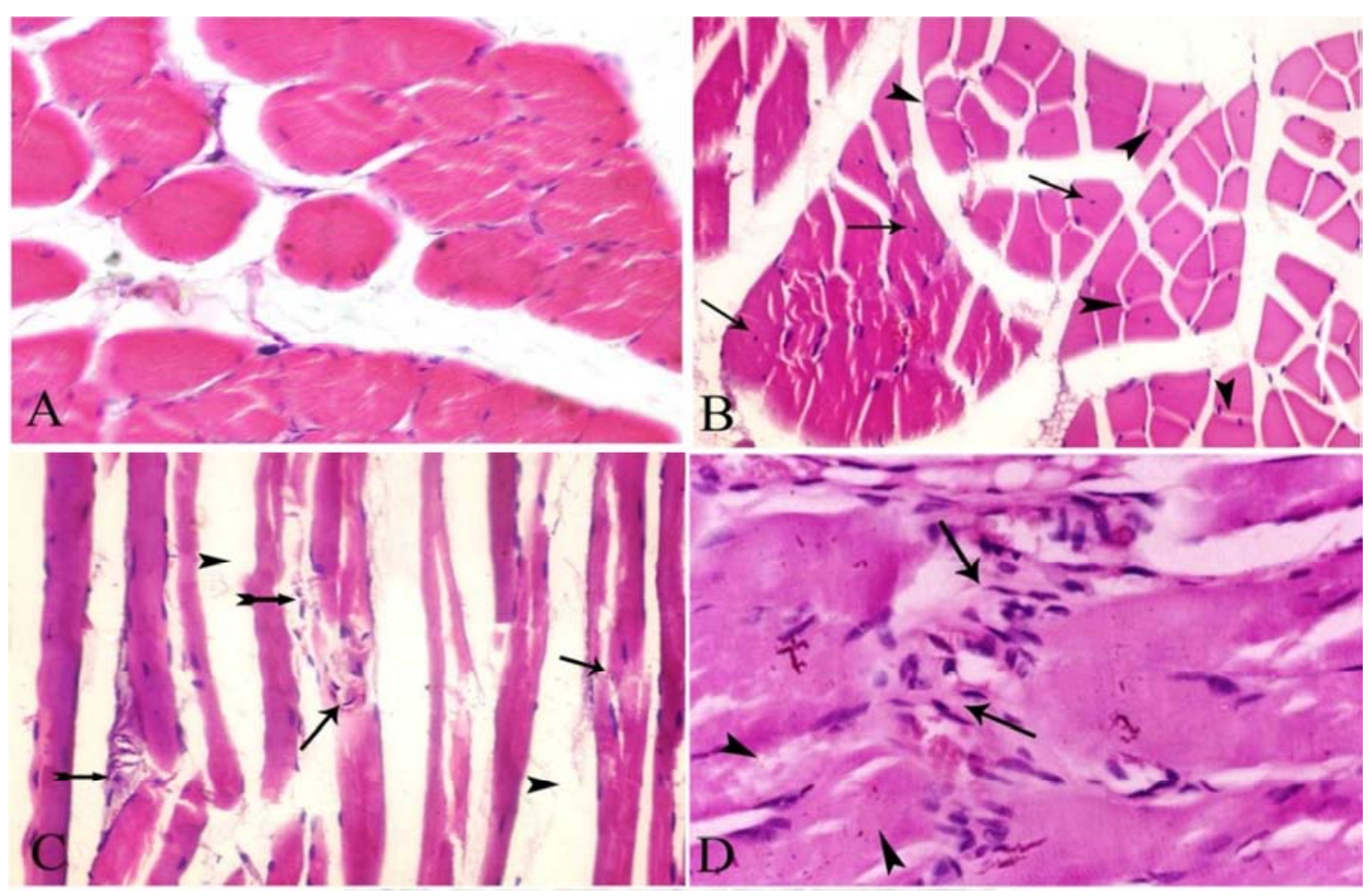

Figure 4. (A) Transverse section of a skeletal muscle of a rat in group 4 showing hypertrophy of most fibers. (B) Transverse section showing increased variation of fiber size \& shape, internal myonuclei $\rightarrow$ ) and increased fiber splitting. (C) Longitudinal section showing widening of the space between muscle fibers (>), disturbed transverse striation and degeneration $(\rightarrow)$ of some muscle fibers with the debris mixed with mononuclear cells $(\rightarrow)$. (D) Longitudinal section showing loss of architecture, fibrous tissue and inflammatory cells replaced the damaged muscle fiber $(\rightarrow)$ and disturbed transverse striations $(\gg)$ ( $H$ $\& E ; A, B \& C x 400, D x 1000)$.

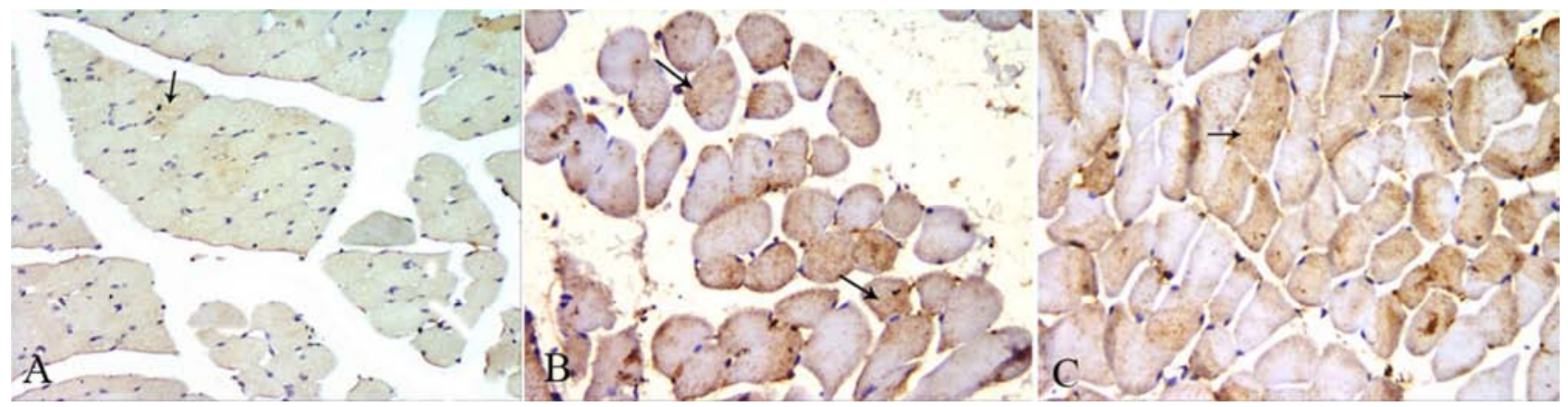

Figure 5. Transverse sections of skeletal muscles of rats showing mild (A), moderate (B) and marked (C) caspase-3 positive immune-reaction in group 2, 3 and 4 respectively $(\rightarrow)$. (Caspase- 3 immunostaining; $X 400)$.
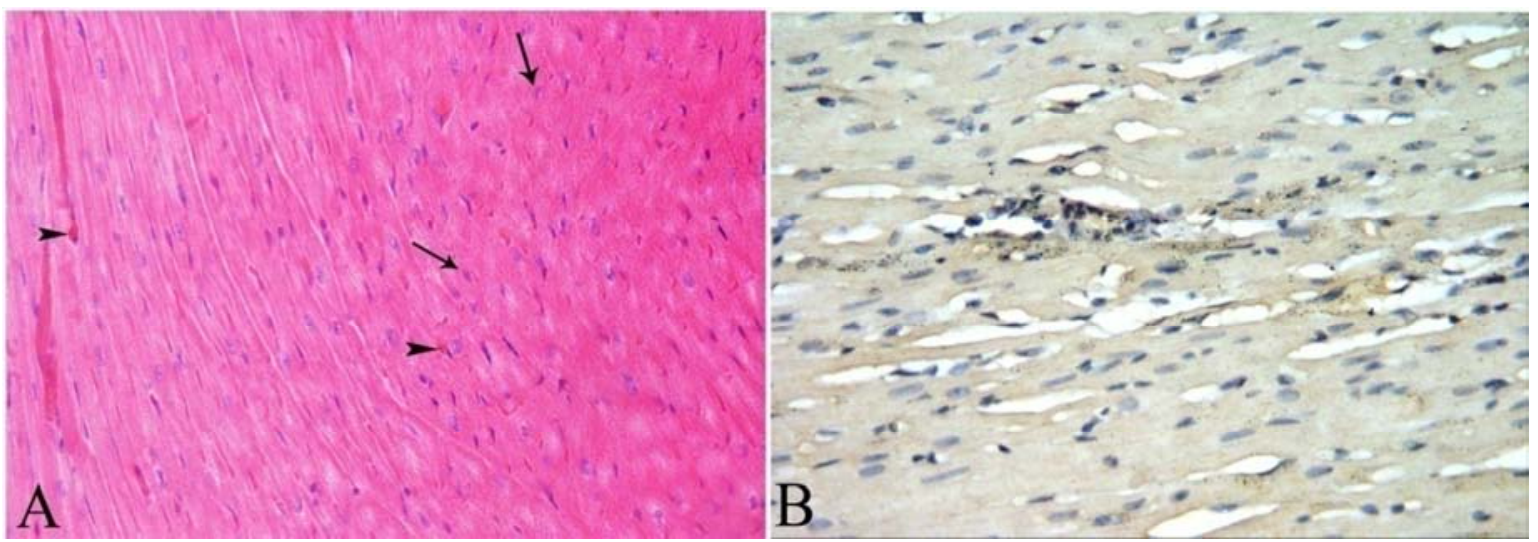

Figure 6. Sections of the cardiac muscle of a control rat showing: (A)Longitudinally and transversely cut cardiac muscle fibers with centrally located nuclei $(\rightarrow)$. Notice the delicate connective tissue separating the cardiac myocytes containing myocardial blood capillaries (>). (B) Very weak or absence of caspase3 positive immuno-reaction ( $A$ : $H \& E ; x$ 400, B: Caspase-3 immunostaining; $x$ 400). 


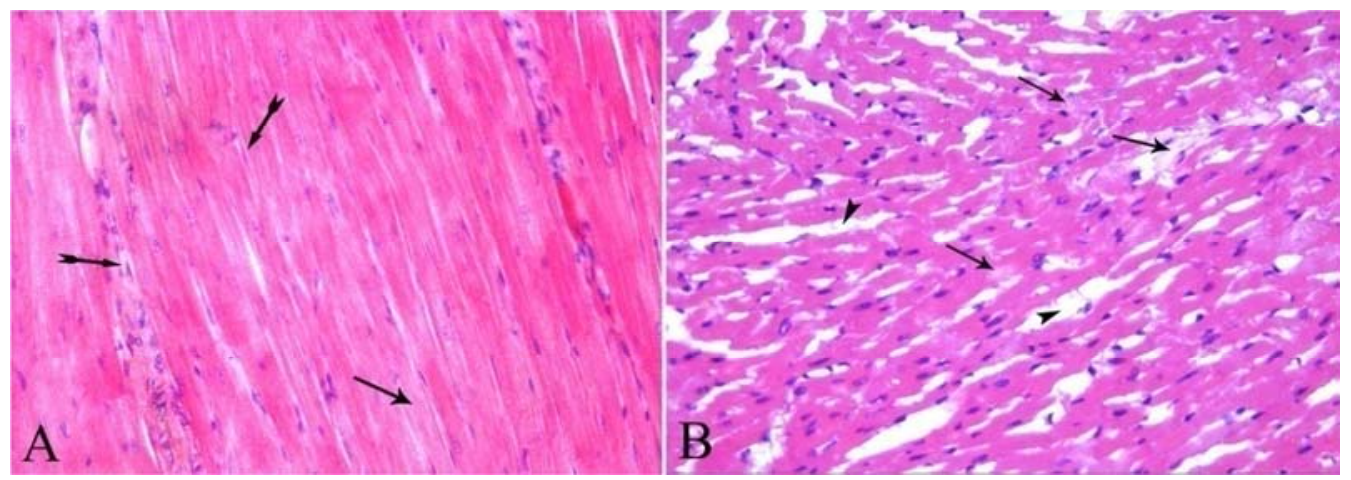

Figure 7. Sections of the cardiac muscle of a rat in group 2 showing: (A) Focal areas of pale sarcoplasm ( $\rightarrow$ ) and increased nuclei of the fibroblasts in between cardiac myocytes $(\rightarrow)$. (B) Focal areas of pale sarcoplasm $\rightarrow$ ) and increase in the connective tissue matrix in between cardiac myocytes $(>)$ (H \& E; $x$ 400).

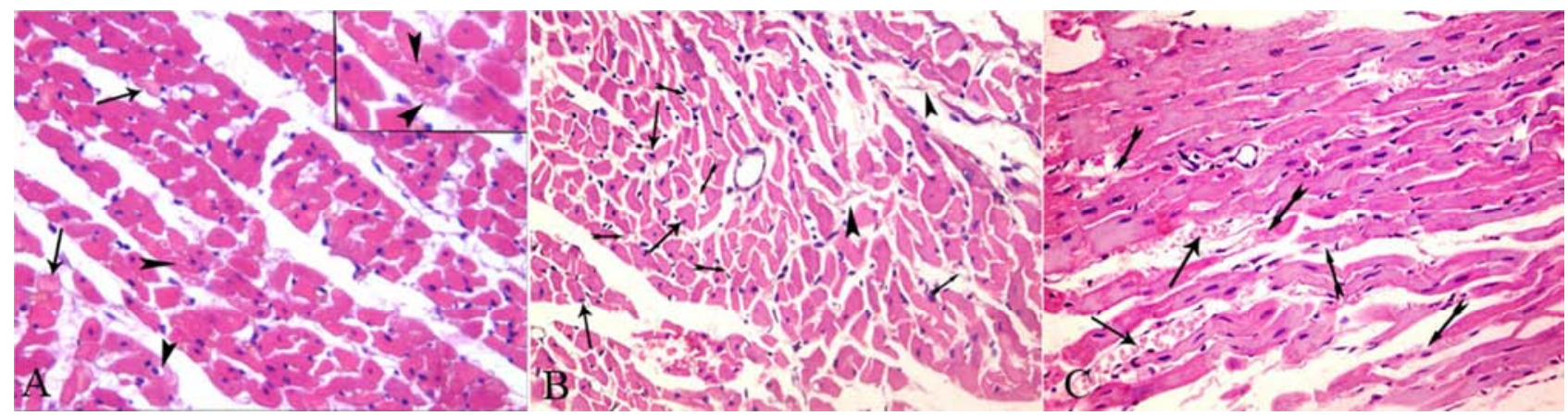

Figure 8. Sections of cardiac muscle of a rat in group 3 showing: (A) Apparent hypertrophy of cardiac myocytes, pale acidophilic cytoplasm ( $\rightarrow$ ) of some myocytes, nuclear peripheralization and cytoplasmic and perinuclear vacuolation (>). (B) Nuclear peripheralization and pyknosis ( $\rightarrow$ ), increase in the connective tissue matrix in between cardiac myocytes (>) and congestion in most blood capillaries ( $\rightarrow$ ). (C) Congestion and dilatation of myocardial blood vessels $\rightarrow$ and fibrillolysis with disturbed transverse striation $(\rightarrow)$. (H\& E; $x$ 400; inset; $x$ 1000).

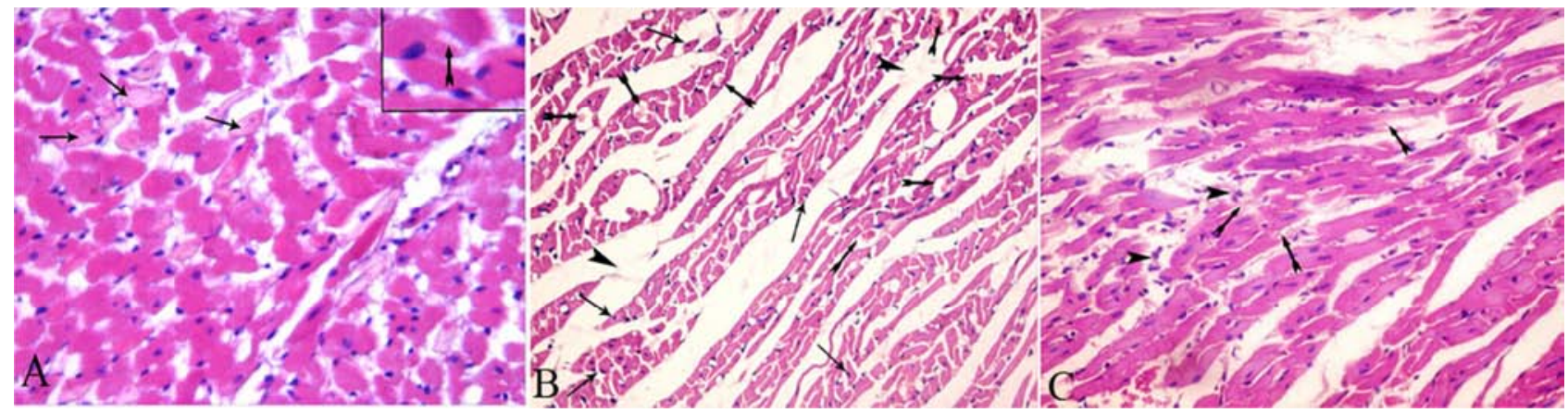

Figure 9. Sections of cardiac muscle of a rat in group 4 showing: (A) Apparent hypertrophy of cardiac myocytes, pale acidophilic cytoplasm ( $\rightarrow$ ) and cytoplasmic vacuolation $(\rightarrow)$. (B) Nuclear peripheralization and pyknosis $(\rightarrow)$, increase in the connective tissue matrix in between cardiac myocytes $(>)$ with dilatation and congestion in most of blood capillaries $(\rightarrow)$. (C) Fibrillolysis with disturbed transverse striation $(\rightarrow)$ and mononuclear cellular infiltration in between cardiac myocytes (>) (H\& E; $x$ 400; inset; $x 1000)$.

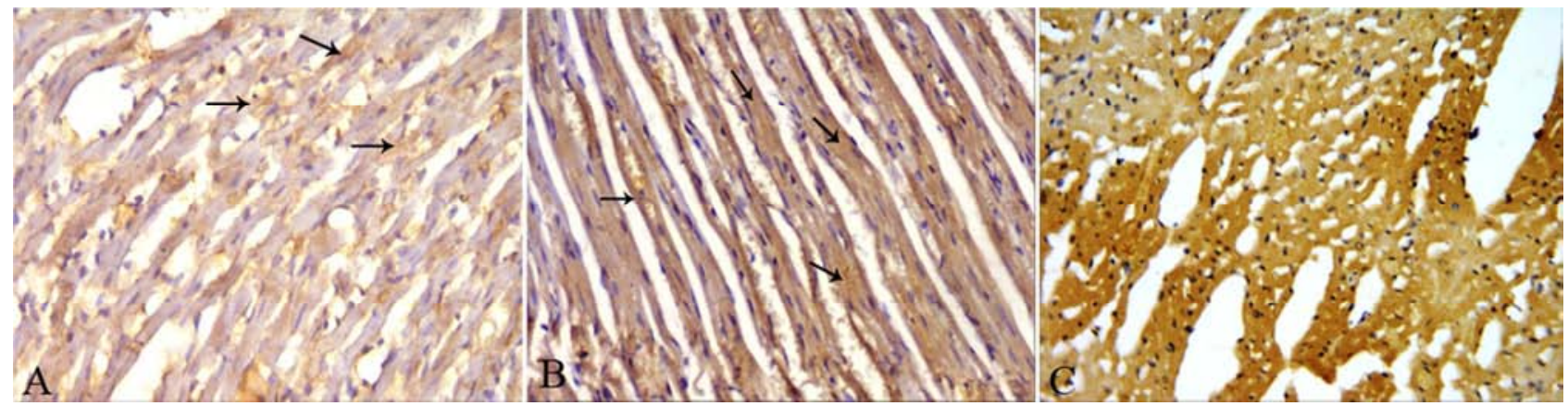

Figure 10. Sections of cardiac muscle of rats of showing mild (A), marked (B) and very marked (C) caspase-3 positive immune-reaction in group 2, 3 and 4 respectively $(\rightarrow$ ). (Caspase-3 immunostaining; X 400). 


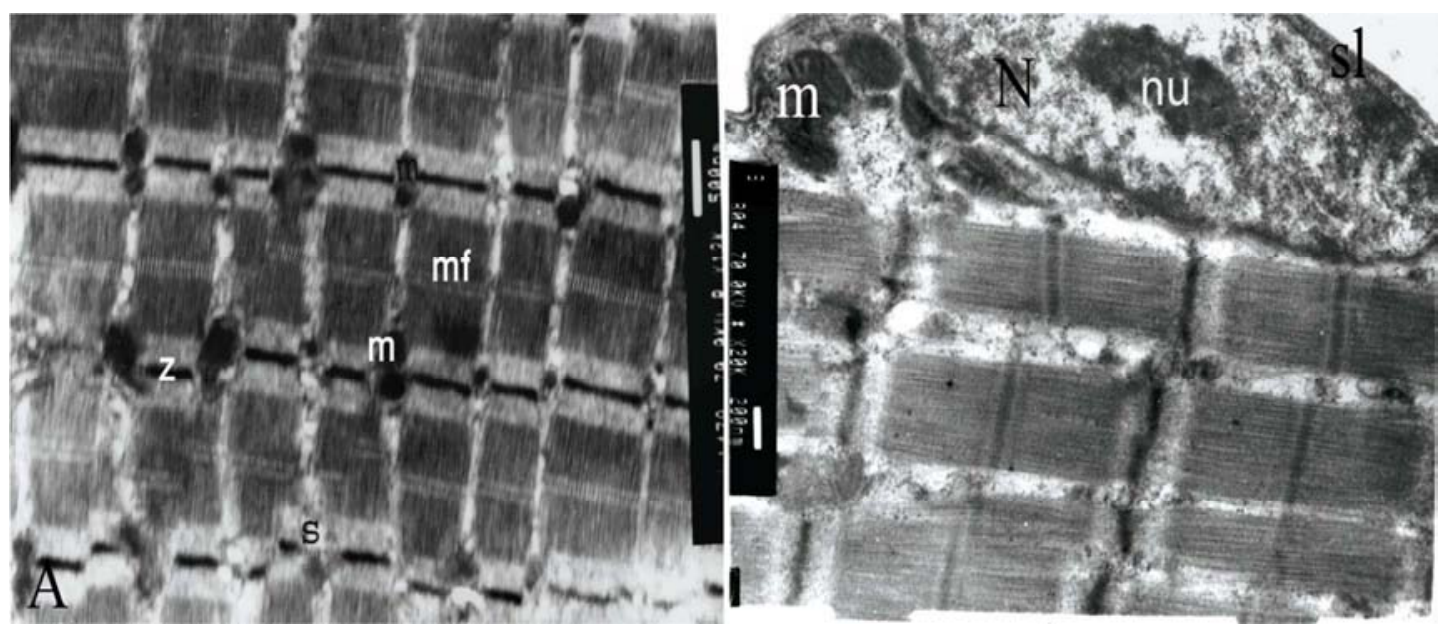

Figure 11. Electron micrographs of longitudinal sections of the skeletal muscle of a control rat showing:) A) Parallel arrangement of myofibrils (mf) with light and dark bands. Sarcomeres are seen between two successive $Z$ lines $(Z)$, mitochondria $(m)$ situated between myofibrils in pairs around $Z$ line. Notice the presence of sarcoplasmic reticulum cisternae (s). (B) Oval elongated nucleus (N) lies just beneath the sarcolemma (sl) with one nucleolus (nu). Few mitochondria (m) are seen under the sarcolemma (sl).

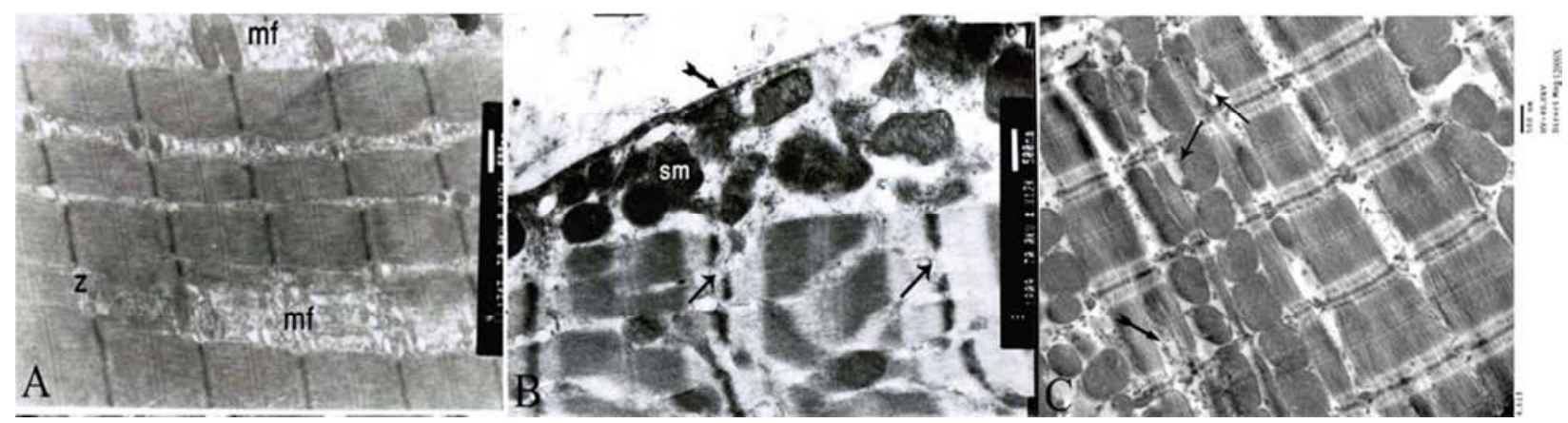

Figure 12. Electron micrographs of a longitudinal section of skeletal muscle of a rat in group 2 showing: (A) Focal areas of degenerated myofibrils (mf) and disruption of $Z$ line (z). (B) Increase in the number of mitochondria (sm) under the sarcolemma ( $\rightarrow)$. Notice focal interruption of $Z$ line $(\rightarrow)$. (C) Accumulated mitochondria in between myofibrils and some of them appear vacuolated $\rightarrow$ and focal lysis of myofibril $(\rightarrow)$.

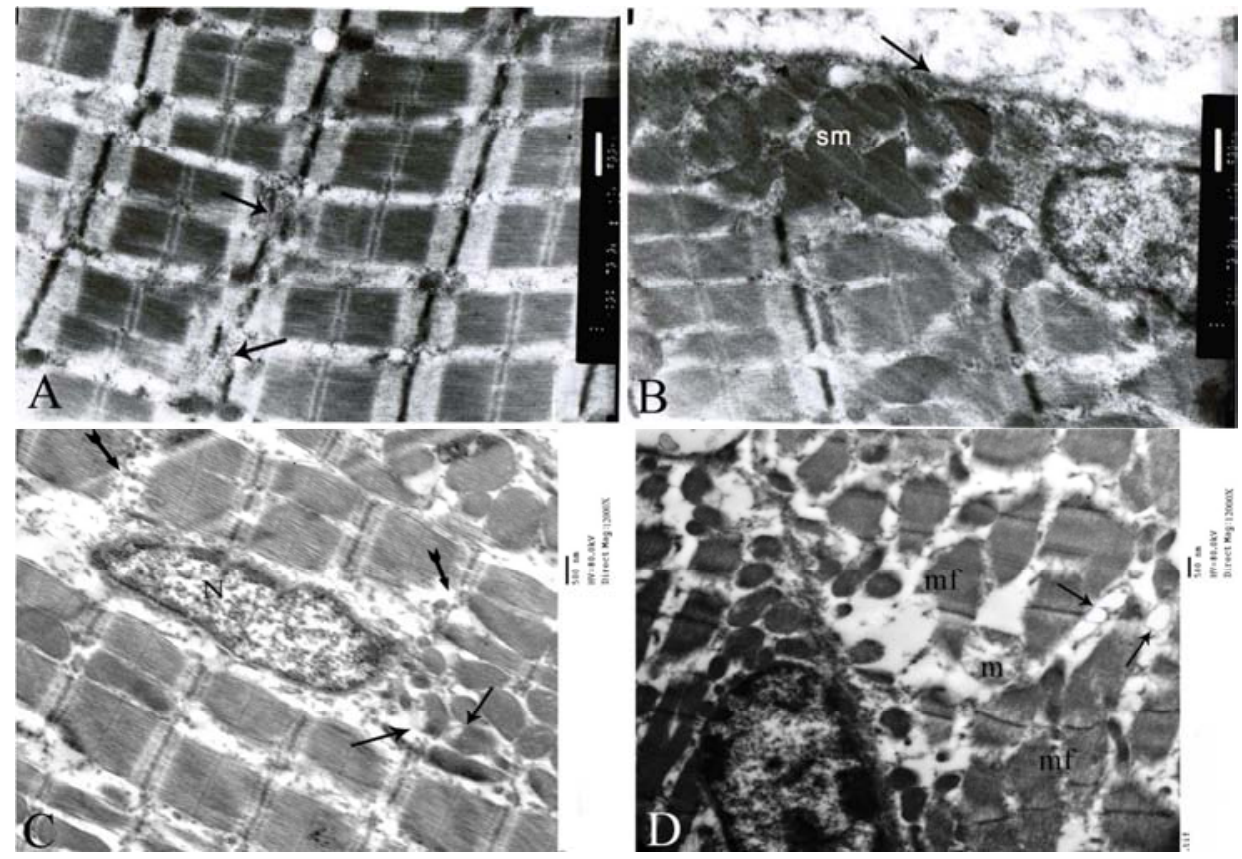

Figure 13. Electron micrographs of longitudinal sections of skeletal muscle of a rat in group 3 showing: (A) Focal disruption of Z line ( $\rightarrow$ ). (B) Accumulation of mitochondria $(\mathrm{sm})$ under sarcolemma $(\rightarrow)$. (C) Accumulated mitochondria in between myofibrils with damaging and vacuolation of some of them $(\rightarrow)$ and internalization of the nucleus $(N)$. Notice focal lysis of myofibril and disruption of $Z$ line $(\rightarrow)$. (D) Dilated sarcoplasmic reticulum $(\rightarrow)$. Notice focal lysis of myofibril ( $m f)$ and swollen and damaged mitochondria $(m)$ 


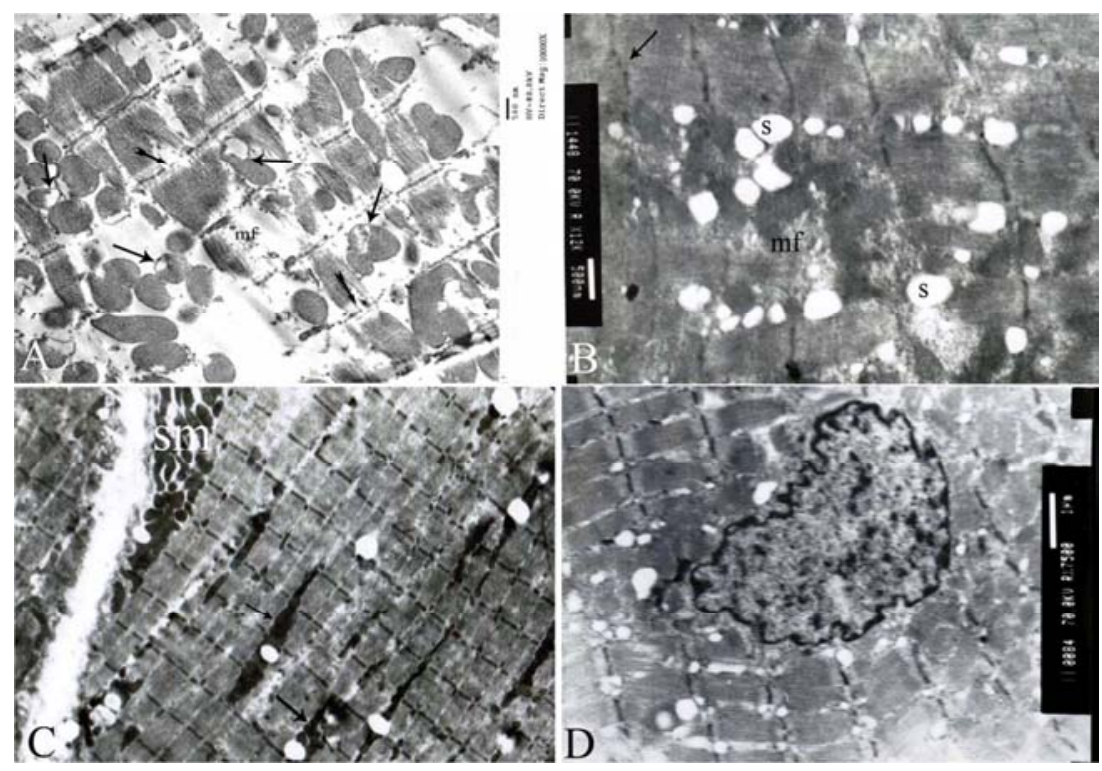

Figure 14. Electron micrographs of longitudinal sections of skeletal muscle of a rat in group 4 showing: (A) disorganization and lysis of the myofibril (mf), disruption of $Z$ line $(\rightarrow)$ and damaged vacuolated mitochondria $(\rightarrow)$. (B) Lysis of the myofibril $(\mathrm{mf})$, disruption of $Z$ line $(\rightarrow)$ and dilated sarcoplasmic reticulum (s). (C) Marked aggregation of mitochondria of different size and shape in subsarcolemmal space (sm) and in the intermyofibrillar space ( $\rightarrow$ ). (D) internalization of the nucleus with irregularity of its outline (n).

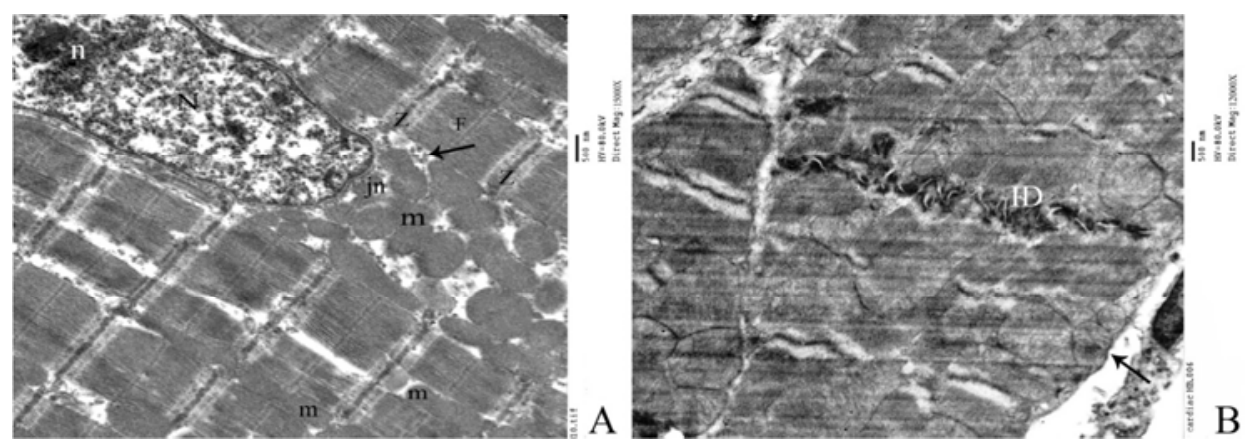

Figure 15. Electron micrographs of the myocardium of the control group showing: (A) Centrally located nucleus (N) with prominent nucleolus (n). Sarcoplasm is composed of longitudinal arrays of cylindrical myofibrils $(F)$ between $Z$ lines passing around the nucleus and outlining a juxtanuclear region (jn) rich in mitochondria $(m)$ and glycogen $(\rightarrow)$ which is also located between the myofibrils. (B) The normal cell membrane of the cardiac myocytes $(\rightarrow)$ and the intercalated disc separating two cardiac myocytes (ID).

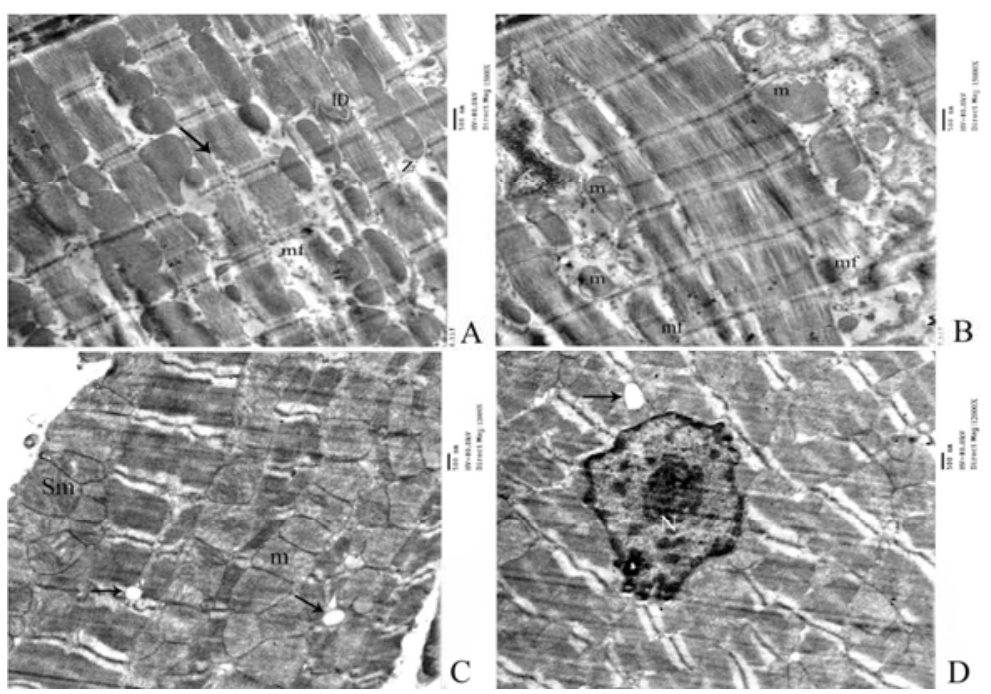

Figure 16. Electron micrographs of the myocardium of a rat in group 2 showing: (A\&B) Loss of the uniform thickness pattern of myofibrils, focal areas of fragmentation and lysis of myofibrils ( $\mathrm{mf}$ ), disruption of $Z$ line (z) and splitting of some fibrilis $(\rightarrow)$. Notice intercalated disc (ID). (B) Some mitochondria appear swollen and vacuolated $(\mathrm{m})$. (C) Accumulated swollen mitochondria (sm) under the sarcolemma and in between myofibrils ( $\mathrm{m}$ ) and dilated sarcoplasmic reticulum $(\rightarrow)$. (D) Irregular outline of the nucleus with clumps of its heterochromatin and dilated sarcoplasmic reticulum $(\rightarrow)$. 


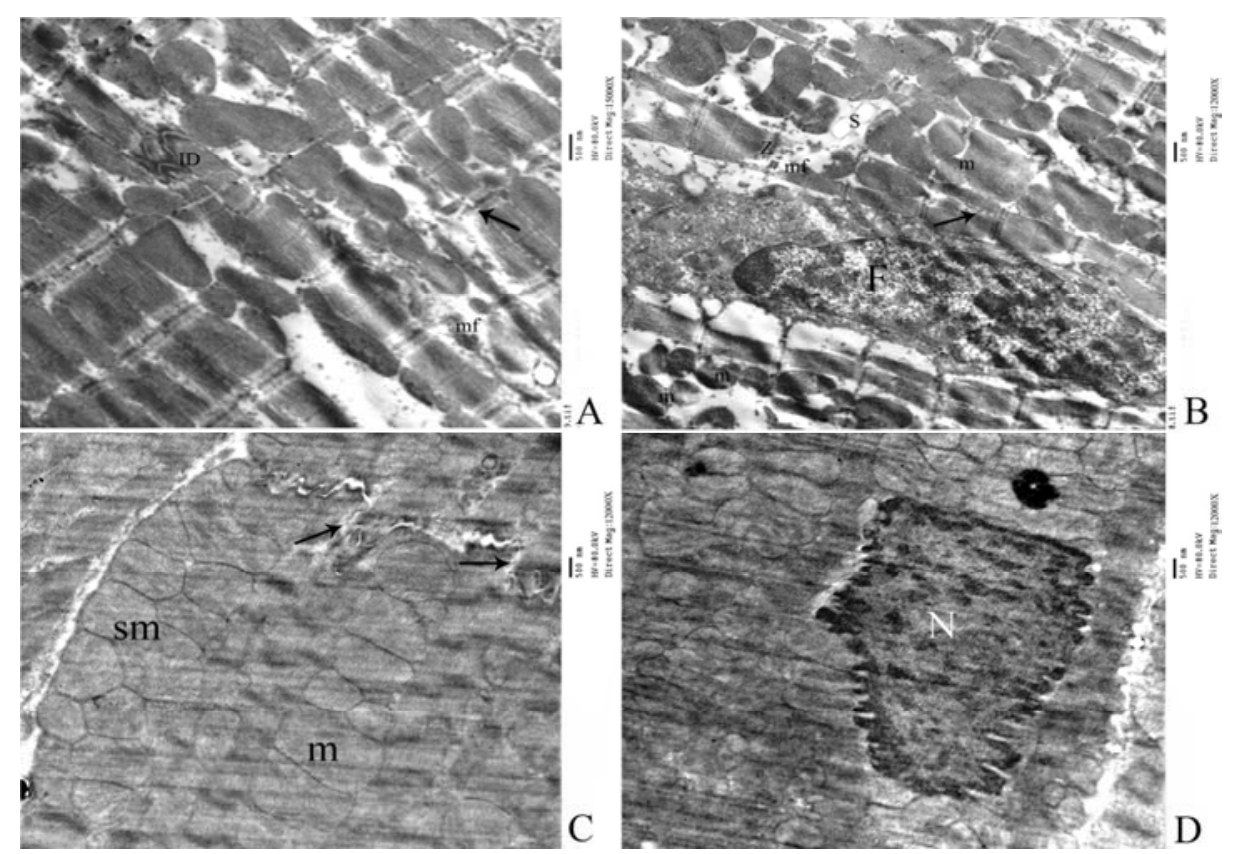

Figure 17. Electron micrographs of the myocardium of a rat in group 3 showing: (A) Destruction and degeneration of some myofibrils (mf), disruption of $Z$ line $(\rightarrow)$ and intercalated disc (ID). (B) Focal areas of myofibrils $(\mathrm{mf})$ lysis, mitochondria appear pleomorphic and some are destroyed and vacuolated $(\mathrm{m})$, dilated sarcoplasmic reticulum $(S)$ and splitting of some myofibrilis $(\rightarrow)$. Notice fibroblast in between myocytes (F). (C) Accumulated swollen mitochondria under the sarcolemma (sm) and in between myofibrils $(m)$ and interruption of the intercalated disc $(\rightarrow)$. (D) Peripheral nucleus with irregular outline and clumping of its heterochromatin (N).
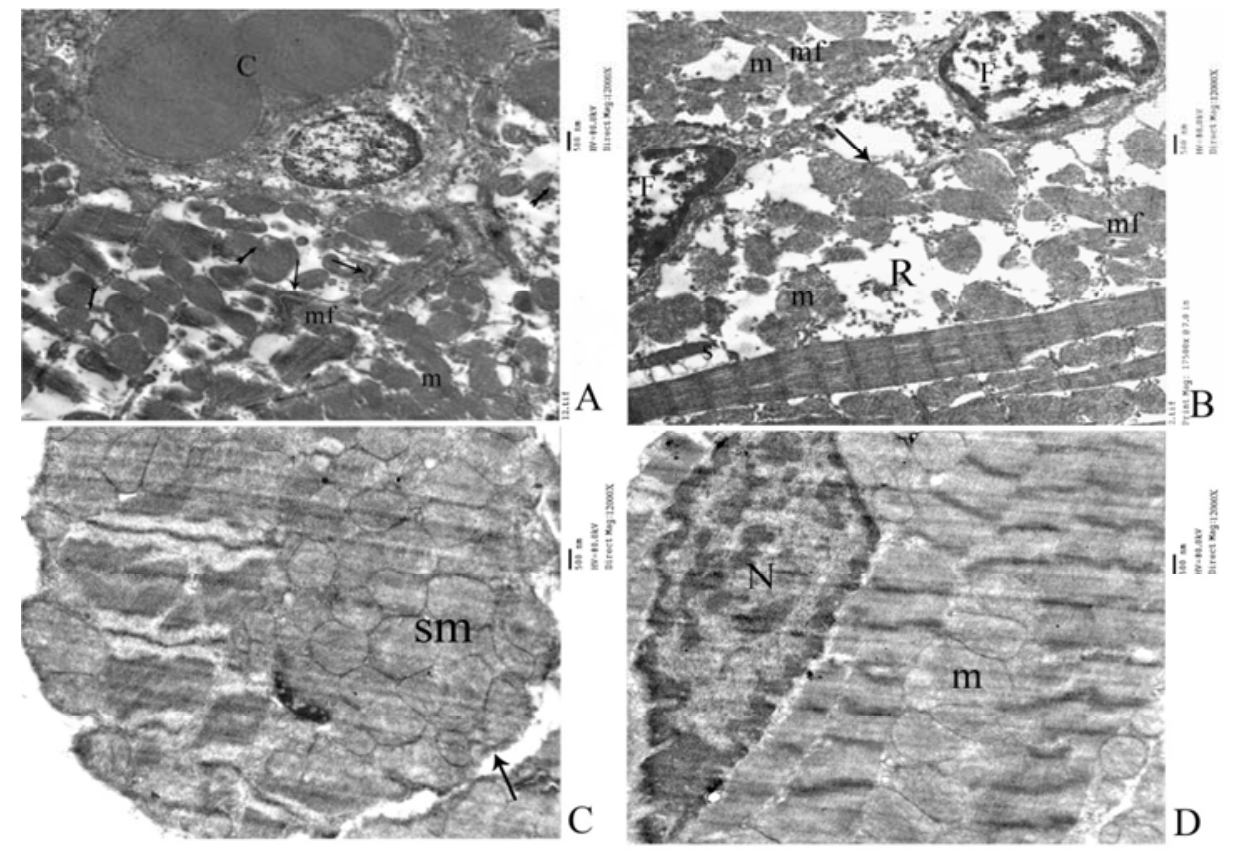

Figure 18. Electron micrographs of the myocardium of a rat in group 4 showing: (A) Disturbance of the normal architecture of myofibrilis ( $m f$ ) with extensive destruction and disorganization, discontinuation and damage of the intercalated disc $(\rightarrow)$ and pleomorphic mitochondria $(m)$ in which some of them appear vacuolated ( $\rightarrow$ ). Notice the presence of dilated congested blood capillary (c). (B) Disorganization and lysis of the myofibrils (mf), areas of sarcoplasmic rarefaction $(R)$ under the sarcolemma $(\rightarrow)$, swollen mitochondria $(m)$ and dilated sarcoplasmic reticulum $(s)$. Notice nuclei of fibroblast cells $(F)$ in between myofibers. (C) Marked aggregation of swollen mitochondria (sm) under the sarcolemma $(\rightarrow)$. (D) Showing peripherlization of the nucleus with irregularity of its outline ( $N$ ) and swollen mitochnodria inbetween myofibrilis $(m)$.

\section{Discussion}

Although androgens increase the nitrogen retention, muscle mass and enhanced strength via increased protein synthesis and metabolism, no pure anabolic steroids exists.
AAS use is mostly linked with different unsafe impacts on health which are commonly dose related [22].

In this work, the periodic records of weight showed that there was significant decrease in body weight gain in rats given high dose when compared to control rats. The work of 
some researchers has shown that treatment of young male rats with an anabolic steroid leads to retardation of their growth $[23,24]$. The retardation of growth takes places when male animals received high doses of the anabolic agent, this does not happen at low doses [23]. It has been observed that in old rats the decrease in body weight values may be associated with a lowering in adipose tissue quantity. It is in fact more commonly noticed in old rats as compared to young rats, as the young ones exhibit little quantities of fat [25]. Decreased appetite and increased fat metabolism provoked by testosterone [26] are the most probable factors concerned with retardation of growth and to reduction in body weight.

In the present work the skeletal and cardiac muscles after 8 weeks of nandrolone decanoate injection appeared hypertrophied as compared with control group. This result also, supported some previous studies [27, 28]. Diel et al. [29] explained that testosterone and its synthetic derivatives act through the androgen receptors (ARs) to increase the size of muscle. Skeletal muscle can be considered as the main target tissue for the anabolic effects of AAS through ARs. They are in general up-regulated and their number increases with body building on exposure to AAS. Also, testosterone stimulates the myocytes to store more contractile protein leading to growth of muscle [27].

It has been described that satellite cells were the predominant site of androgen receptor expression [30]. Sinha-Hikim et al. [31] stated that testosterone supplementation induced hypertrophy of skeletal muscle by inducing satellite cell activation as well as replication leading to an increase in the mean number of satellite cells per unit length of muscle fiber. Some researchers stated that the augmentation in muscular power and the hypertrophy of the fibers caused by steroid occurs when it was used and accompanied with powerful physical exercise and with high protein and calorie consumption [32]. In the present research, although the applied diet was balanced and no intense physical exercise was applied, the skeletal and cardiac muscles fibers were hypertrophied. This is in agreement with Sinha hikim et al. [31] who denoted that testosterone use in community-dweling older men had dose linked hypertrophy of both type I and II skeletal muscle fibers.

In this study the cardiac muscle of rats exposed to nandrolone decanoate injection for 8 weeks was hypertrophied as compared to the control rats. Tanno et al. [33] revealed hypertrophy of cardiac muscle in male rats administrated nandrolone, without intense exercise practice. Franquni et al. [14] showed that hypertrophied cardiac myocytes had deposition of collagen in extracellular matrix and also expressed disturbance in cardiac cytokines with predominance of pro-inflammatory ones. Myocardial cells have been shown to have a high affinity for androgens [34].

In the current study, internal migration of sarcolemmal nuclei and longitudinal splitting of skeletal muscle fibers were observed. It has been stated that splitting of muscle fibers is an adaptive response occurs when the fiber reaches a critical size at which exchanges of the metabolites and also supplies of oxygen are not efficient [35]. They also suggested that nuclear migration plays a part in muscle fiber splitting pathogenesis and concluded that such changes may occur in muscle fibers, which have undergone over work [36].

Satellite cells served as the origin of new myofiber nuclei and their excitation could cause their proliferation and differentiation into new myotubes which fuse with the existent muscle fibers. During the process of fusion, some myonuclei may remain in the central area of the out coming new and larger fiber. This central myonuclei is needed for the growth of the new fiber when new myotubes unite with the already existing muscle fiber [30, 34, 37].

However, cardiac myocytes of nandrolone treated rats displayed peripherally located nuclei. It has been described that desmin; the cytoskeletal intermediate filaments forms a sarcoplasmic network diverging from the sarcolemma to the nuclear surface very close to the nuclear pores. Disruption of this cytoskeleton by the activation of protease enzymes during nandrolone administration would be responsible for nuclear displacement of the cardiac myocytes [38-39].

The widening of the interstitial tissue in both skeletal and cardiac muscles, which was detected in the current study could be the result of progressive increase in the connective tissue elements, especially collagen fibers, and was concomitant with the degree of muscle damage. Loss of the contractile ability of the heart could be attributed to the collagen associated with cardiac hypertrophy and increased stiffness or decreased compliance of the ventricular wall which may give rise to heart failure [40]. It has been documented that the increase of intrafasicular connective tissue usually represent a response to a loss of myofibers and attributed that to cytokine imbalance [14, 41].

The present work showed dilatation and congestion of blood vessels in both skeletal and cardiac muscles and even extravasation of blood in the interstitial tissue. Previous studies [42] cited that AAS treatment prompted oxidative stress in rats which could lead to dilatation and congestion of blood vessels as well as the release of vasodilator materials that increase the permeability of the endothelial lining of blood vessels resulting in outpouring of blood elements into the extravascular tissue.

In this study, destroyed mitochondria amongst other cytoplasmic organelles were found in treated groups in skeletal and cardiac muscles. But, the mitochondrial findings were different among previous workouts using AAS. Satoh et al. [43] observed that nandrolone gave rise to a raised mean cross sectional area of mitochondria in muscle fibers of diaphragm after about 4 weeks of exposure. While others [44] showed that mitochondria in the cardiac muscles of adult albino rats with injection of sustanon, as an example of AAS had sparse matrix with few cristae, swollen and pleomorphic. It has been stated that abnormalities of the mitochondrial morphology are mostly associated with defects of the respiratory chain. They added that 'ragged-red' fibers are muscle with prominent subsarcolemmal aggregations of mitochondria and referred the proliferation to a trial by the cell to recompense for the respiratory chain deficiency and reduction in cytochrome $\mathrm{C}$ oxidase activity [35]. 
subsarcolemmal accumulations of mitochondria would happen as a response to metabolic stress [45]. The previous results were the same as with our demonstration and can explain the accumulation of subsarcolemmal mitochondria in the current research.

Myofibril disassembly reported in the current study may be due to the action of a calcium activated proteinase (CAP) in necrotic muscle. Proteinase is activated by calcium ion as its level rise to its extracellular level after breaching of the plasmalemma in necrotic muscle, thus disassembly occurred by digesting out $\mathrm{Z}$ lines, $\mathrm{M}$ lines, $\mathrm{C}$ proteins, tropomyosin and troponins $\mathrm{T}$ and $\mathrm{I}$ from the myofibrils and thus fragmentation of myofilaments occurred [35]. In addition, myofibrillar disassembly may be due to damage of mitochondrial with inadequate energy production, which is needful for the preservation of cell homeostasis and renewal of cellular proteins [46].

Apoptosis is the programmed death of a cell and is brought about by either through an extrinsic death receptor signaling pathway or the intrinsic mitochondrial pathway. Caspases exert significant action in both pathways and acts as a mediator of apoptosis in mammalian cells. Caspase- 3 is a member of mammalian proteases. Members of this family have been involved in apoptosis. Caspase-3 is produced as an inactive proenzyme and during apoptosis changes to its active form [47].

The histopathological lesions in the current study were correlated with expression of caspase-3 which was highly increased in nandrolone treated rats compared to the control rats in groups received moderate and high doses of nandrolone in skeletal muscle and in all doses used in cardiac muscle indicating apoptosis in those cells. The current results are in line with that described by Papamitsou et al. [15] who reported that AAS increased immunoexpression of caspase-3 in the myocardial tissue of adult male rats. Testosterone causes apoptosis in vascular smooth muscle cells by the extrinsic pathway and involve androgen receptor activation and mitochondria-generated reactive oxygen species (ROS) [16]. Previous investigations confirm the fact that apoptosis of cardiomyocytes is an important phenomenon in the process of change between compensatory cardiac hypertrophy and heart failure [48]. Apoptosis might be explained by the ability of testosterone and its synthetic derivatives to induce ROS generation which decreases cell viability by increasing mediators of apoptosis and thus activation of cell death programmes $[16,49]$.

The degenerative changes noted on observation under light microscope as well as those in membranous organelles like mitochondria and sarcoplasmic reticulum, viewed under electron microscope in skeletal and cardiac muscles in the current study could be due to the fact that androgens work by receptor-dependent and receptor-independent mechanisms. Androgen receptors are found in the skeletal muscles and cardiovascular system; including human vascular endothelium, smooth muscle cells, macrophages, and cardiac myocytes. Nandrolone directly modifies transcription, translation and enzyme action after binding with androgen receptors in the cardiac and skeletal muscles. Resultant changes of cellular pathology and organ physiology are familiar with those observed in cardiomyopathy and heart failure. High blood pressure, myocardial ischemia, ventricular remodeling and sudden cardiac death have also been temporally and causally related to anabolic steroid use in humans [29, 44, 50].

Nandrolone could act through antagonizing or down regulating the mechanisms involved in the enhancement of antioxidant defenses. ATP depletion resulted from defective mitochondrial functions leads to activation of phospholipase enzyme and disintegration of phospholipids. Peroxidation of the lipid of in the biological membranes causes dysfunction, inactivation of membrane enzymes and receptors, raised of permeability to ions and a disturbance in membrane structure. A probable reason could be the accumulation of calcium, which leads to dysfunction of the mitochondrial and lowering in ATP generation $[38,51]$.

\section{Conclusion}

It could be concluded that, nandrolone decanoate injection in male albino rats induced hypertrophy and degenerative changes in the skeletal and cardiac muscles which may lead to loss of their functions and damage to them. Testosterone or its derivatives such as AAS are being abused at supraphysiological doses and they may cause considerable harm. Athletes, coaches, and physicians should be aware of their harmful side effects.

\section{References}

[1] Lee DM, Mina T, Choi I, Cheon YP, Chun T, Park C S, Lee KH. Feeding Effect of an Anabolic Steroid, Nandrolone, on the Male Rat Testis. Asian-Aust J Anim Sci. 2010; 23 (12): 15661577 .

[2] Salas-Ramirez K Y, Montalto PR, Sisk CL. Anabolic androgenic steroids differentially affect social behaviors in adolescent and adult male Syrian hamsters. Horm Behav. 2008; 53: $378-385$.

[3] Kicman AT. Pharmacology of anabolic steroids. $\mathrm{Br}$ J Pharmacol. 2008; 154 (3): 502-521.

[4] Oberlander JG, Porter DM, Penatti CA, Henderson LP. Anabolic androgenic steroid abuse: multiple mechanisms of regulation of GABAergic synapses in neuroendocrine control regions of the rodent forebrain. J Neuroendocrinol. 2012; 24 (1): $202-214$

[5] Powers M. Performance-Enhancing Drugs. Principles of Pharmacology for Athletic Trainers, Houglum J, Harrelson GL, eds. (2nd ed.). SLACK Incorporated. 2011; P: 345.

[6] Sjöqvist F, Garle M, Rane A. Use of doping agents, in particular anabolic steroids, in sports and society. Lancet. 2008; 371 (9627): 1872-1882.

[7] Saha B, Rajadhyaksha GC, Ray SK. Beneficial effects of nandrolone decanoate in wasting associated with HIV. J Indian Med Assoc. 2009; 107 (5): 295-299. 
[8] Narayanan R, Mohler ML, Bohl CE, et al. Selective androgen receptor modulators in preclinical and clinical development. Nucl Recept Signal 2008; 6: e010.

[9] Zhang X, Sui Z. Deciphering the selective androgen receptor modulators paradigm. Expert Opin Drug Discov. 2013; 8: 191218.

[10] Fitch KD. Androgenic-anabolic steroids and the Olympic Games. Asian J Androl. 2008; 10 (3): 384-390.

[11] Pope HG Jr, Khalsa JH, Bhasin S. Body Image Disorders and Abuse of Anabolic-Androgenic Steroids Among Men. JAMA. $2017 ; 3 ; 317$ (1): 23-24

[12] Du Toit E F, Rossouw E, Van Rooyen J, Lochner A. Proposed mechanisms for the anabolic steroid-induced increase in myocardial susceptibility to ischaemia/reperfusion injury. Cardiovasc J S Afr. 2005; 16: 21-28.

[13] Crisostomo PR, Wang M, Wairiuko GM, Morrell ED, Meldrum DR. Brief exposure to exogenous testosterone increases death signaling and adversely affects myocardial function after ischemia. Am J Physiol Regul Integr Comp Physiol. 2006; 290: R1168-R1174.

[14] Franquni JV, do Nascimento AM, de Lima EM, et al. Nandrolone decanoate determines cardiac remodeling and injury by an imbalance in cardiac inflammatory cytokines and ACE activity, blunting of the Bezold-Jarisch reflex, resulting in the development of hypertension. Steroids. 2013; 78 (3): 379385.

[15] Papamitsou T, Barlagiannis D, Papaliagkas V, Kotanidou E, Dermentzopoulou-Theodoridou M. Testosterone-induced hypertrophy, fibrosis and apoptosis of cardiac cells--an ultrastructural and immunohistochemicalstudy. Med Sci Monit. 2011; 17 (9): BR266-273.

[16] Lopes RA, Neves KB, Pestana CR, et al. Testosterone induces apoptosis in vascular smooth muscle cells via extrinsic apoptotic pathway with mitochondria mitochondria-generated reactive oxygen species involvement. Am J Physiol Heart Circ Physiol. 2014; 306 (11): H1485-H1494.

[17] Fanton L, Belhani D, Vaillant F, et al. Heart lesions associated with anabolic steroid abuse: Comparison of post-mortem findings in athletes and norethandrolone-induced lesions in rabbits. Exp Toxicol Pathol. 2009; 61 (4): 317-323.

[18] Saffitz, J E. The hear, Ch: 11 in Essential Pathology, Rubin E. (editor), $6^{\text {th }}$ ed. Lippincott Wiliams\& Wilkins. 2014; P: 281316.

[19] Bancroft JD, Layton C. The Hematoxylins and Eosin, Ch: 10 In: Theory and Practice of histological techniques, 7th edition, (eds S. K. Suvarna, C. Layton, J. D. Bancroft), London: Churchill Livingstone, 2012; P: 173-214.

[20] Jackson P, Blythe D. Immunohistochemical techniques, Ch 18 In: Theory and Practice of histological techniques, 7th edition, (eds S. K. Suvarna, C. Layton, J. D. Bancroft), London: Churchill Livingstone, 2012; P: 381-426.

[21] John K. Electron Microscopy Methods and Protocols, methods in molecular biology, $3^{\text {rd }}$ edition, Springer, New York, 2014.

[22] Hildebrandt T. Abuse of performance-enhancing drugs. Ch 96; in Pfaff DW. (editor) Neuroscience in the 21st Century from Basic to Clinical. New York, Springer New York. 2013; P: 2813-2832.
[23] Bisschop A, Gayan-Ramirez G, Rollier H, et al. Effects of nandrolone decanoate on respiratory and peripheral muscles in male and female rats. J Appl Physio. 1997; 82: 1112-1118.

[24] Fontana K, Campos GER, Staron RS, da Cruz-Höfling MA. Effects of Anabolic Steroids and High-Intensity Aerobic Exercise on Skeletal Muscle of Transgenic Mice. PLoS ONE. 2013; 8 (11): e80909.

[25] Carson JA, Lee WJ, McClung J, Hand G A. Steroid receptor concentration in aged rat hindlimb muscle: effect of anabolic steroid administration. J Appl Physiol. 2002; 93: 242-250.

[26] Foletto MP, Ferrari F, Pere SB, de Morae SMF, Segatelli TM, Mareze-da-Costa CE. Effects of anabolic steroid treatment associated with physical training in adipose tissue of male Wistar rats. Acta Scientiarum Health Sciences. 2015; 37: 1924.

[27] Dela Cruz C, Agati Leandro B, Pereira Oduvaldo C. M. Effects of Nandrolone Decanoate and Resistance Exercise on Skeletal Muscle in Adult Male Rats. Int. J. Morphol. 2012; 30 (2): 613620.

[28] Do Nascimento AM, Lima EM, Brasil GA, et al. Serca2a and $\mathrm{Na}(+) / \mathrm{Ca}(2+)$ exchanger are involved in left ventricular function following cardiac remodelling of female rats treated with anabolic androgenic steroid. Toxicol Appl Pharmacol. 2016; 15 (301): 22-30.

[29] Diel P, Friedel A, Geyer H, et al. The prohormone 19norandrostenedione displays selective androgen receptor modulator (SARM) like properties after subcutaneous administration. Toxicol Lett. 2008; 177 (3): 198-204.

[30] Sinha-Hikim I, Taylor WE, Gonzalez-Cadavid NF, Zheng W, Bhasin S. Androgen receptor in human skeletal muscle and cultured muscle satellite cells: up-regulation by androgen treatment. J Clin Endocrin Metab. 2004; 89: 5245-5255.

[31] Sinha-Hikim I, Cornford M, Gaytan H, Lee ML, Bhasin S. Effects of Testosterone Supplementation on Skeletal Muscle Fiber Hypertrophy and Satellite Cells in Community-Dwelling Older Men. J Clin Endocrinol Metab. 2006; 91 (8): 3024-3033.

[32] Filho JCJCS, Vanderlei LCM, Camargo RCT, Francischeti FA, Belangero WD, Pai VD. Effects of the anabolic steroid nandrolone on the soleum muscle of rats submitted to physical training through swimming: histological, histochemical and morphometrical study. Rev Bras Med Esporte. 2006; 12, (5): 243-247.

[33] Tanno AP, das Neves VJ, Rosa KT, et al. Nandrolone and resistance training induce heart remodeling: role of fetal genes and implications for cardiac pathophysiology. Life Sci. 2011; 89: 631-637.

[34] Kadi F. Cellular and molecular mechanisms responsible for the action of testosterone on human skeletal muscle. A basis for illegal performance enhancement. Br J Pharmacol. 2008; 154 (3): $522-528$.

[35] Cullen MJ, Johnson MA, Mastaglia FL. Pathological reactions of skeletal muscle, Ch: 3, in, Mastaglia, F. L. and Walton, 1. (eds.) Skeltal Muscle Pathology, Churchill Livingstone, Edinburgh, London, New York, Philadelphia, Sanfrancisco, Sydney, Toronto. 2001; P: 123-184.

[36] Kuang S, Rudnicki MA. The emerging biology of satellite cells and their therapeutic potential. Trends Mol. Med. 2008; 14: 8291. 
[37] Ribeiro BG, Fernandes K PS, Silva MT, Sierra SO, Bussadori $S K$, Mesquita-Ferrari R A. Effects of nandrolone decanoate on the viability of muscle satellite cells during the differentiation process. Fisioterapia e Pesquisa. 2014; 21 (1): 16-20.

[38] Vicencio JM, Estrada M, Galvis D, et al. Anabolic androgenic steroids and intracellular calcium signaling: a mini review on mechanisms and physiological implications. Mini Rev Med Chem. 2011; 11 (5): 390-398.

[39] Sequeira V, Nijenkamp LL, Regan JA, van der Velden J. The physiological role of cardiac cytoskeleton and its alterations in heart failure. Biochim Biophys Acta. 2014; 1838: 700-722.

[40] Montera MW, Drumon C, Takiya C, Mesquita CT, Dohmann HFR, Mady C. Correlation of myocardial interstitial collagen in the right ventricular septum with ventricular function of patients with ischemic cardiomyopathy. Arq. Bras. Cardiol. 2009; 92: 52-60.

[41] Mann CJ, Perdiguero E, Kharraz Y, et al. Aberrant repair and fibrosis development in skeletal muscle. Skelet Muscle. 2011; 4 (1): 21

[42] Sadowska-Krepa E, Kłapcińska B, Jagsz S, Sobczak., Chrapusta SJ, Chalimoniuk M, Grieb P, Proprzęcki. S, Langfort J. High-Dose Testosterone Propionate Treatment Reverses the Effects of Endurance Training on Myocardial Antioxidant Defenses in Adolescent Male Rats. Cardiovasc Toxicol. 2011; 11: $118-127$

[43] Satoh K, Gotoh T, Yamashita K. Morphological effects of an anabolic steroid on muscle fibres of the diaphragm in mice. J Electron Microsc. 2000; 49 (4): 531-538.
[44] Hassan NA, Salem MF, Sayed MA. Doping and effects of anabolic androgenic steroids on the heart: histological, ultrastructural, and echocardiographic assessment in strength athletes. Hum Exp Toxicol. 2009; 28 (5): 273-283.

[45] Kavazis AN, Alvarez S, Talbert E, Lee Y, Powers SK. Exercise training induces a cardioprotective phenotype and alterations in cardiac subsarcolemmal and intermyofibrillar mitochondrial proteins. Am J Physiol Heart Circ Physiol. 2009; 297: H144H152.

[46] Baines CP. The cardiac mitochondrion: nexus of stress. Annu Rev Physiol. 2010; 72: 61-80.

[47] Kroemer G, Galluzzi L, Vandenabeele P, et al. Classification of cell death: recommendations of the Nomenclature Committee on Cell Death. Cell Death and Differentiation. 2009; 16: 3-11.

[48] Chiong M, Wang ZV, Pedrozo Z, et al. Cardiomyocyte death: mechanisms and translational implications. Cell Death Dis. 2011; 2: e244.

[49] Mayada RF, Taghred MS, Haytham AA. Boldenone-induced apoptotic, structural, and functional alterations in the liver of rabbits. World Rabbit Sci. 2015, 23: 39-46.

[50] Lizotte E, Grandy SA, Tremblay A, Allen BG, Fiset C. Expression, distribution and regulation of sex steroid hormone receptors in mouse heart. Cell Physiol Biochem. 2009; 23: 7586.

[51] Chaves EA, Fortunato RS, Carvalho DP, Nascimento JH, Oliveira MF. Exercise-induced cardioprotection is impaired by anabolic steroid treatment through a redox-dependent mechanism. J Steroid Biochem Mol Biol. 2013; 138: 267-272. 